\title{
Lithology effects on the fractures parameters using image log and petrophysical data
}

\author{
Bahman Soleimani ${ }^{1}$, Khayyam Amiri ${ }^{1}$, Babak Samani ${ }^{1}$, and Leila Shaban ${ }^{2}$ \\ Received 22 October 2016; accepted 1 November 2016; published 21 November 2016.
}

Fractures within a reservoir play an influential role in the porosity and permeability, therefore affect the fluid flow. By analyzing properties of fractures, such as fracture height, density and mutually spacing and compare them with different tectonic locations and different lithologies, one could gain insight in the mechanical behavior of a rock mass, when distorted by tectonic forces. The velocity deviation log (VDL) can be used for determination of effective porosity. The result indicated that there is a high fractures density in the Asmari Formation which shows high correlation with VDL. They are mainly strike N75E, S75W direction and are chiefly observed in the upper Asmari zones. Fractures and vuggy have been also observed in the well. Image log showed a range of bedding dip from 53-89 degree with strike N55W, S55E in the well indicating of reverse limb in the field. Image log show tow set fracture which azimuth 347 for discontinuous fracture and 220 with strike N55W, S55E for continuous fracture. Main type of lithology determined by petrophysical $\log$ showed that dolomite is dominant constituent. Induced fractures and breakouts haven't seen observed in this well. After correlating image logs with VDL and lithology, zones with dominant pure dolomite presented higher aperture rather zones with dolomite and anhydrite. Fracture density is more affected by bed thickness to mineralogy. Zones with negative deviation velocity have high fracture density or high fracture aperture. KEYWORDS: Asamari formation; velocity deviation log; image log; fracture; gachsaran oil field.

Citation: Soleimani, Bahman, Khayyam Amiri, Babak Samani, and Leila Shaban (2016), Lithology effects on the fractures parameters using image log and petrophysical data, Russ. J. Earth. Sci., 16, ES5005, doi:10.2205/2016ES000581.

\section{Introduction}

Fractures have a vital effect in production rate and migration of oil in Zagros basin [Alavi, 2004, 2007]. Fractures in carbonate reservoirs are important due to their high influence on reservoir rock properties that deal with porosity and permeability [Nelson, 2001. Rajabi et al., 2010. Two main categories of factors controlled fracture generation in folded structures: (1) geomechanical properties such as lithology, porosity, grain size and fabric of beds and (2) geometrical factors such as: bedding thickness and structural setting [Nelson, 2001]. Knowledge about fracture and their scattering patterns are helping in determination of the best location for drilling and maximum production rate [Serra and Serra, 2004. There are several direct and indirect methods to determine fractures in reservoirs such as seismic, petrophysical

\footnotetext{
${ }^{1}$ Department of Geology, Shahid Chamran University of Ahvaz, Ahvaz, Iran

${ }^{2}$ National South Iranian Oil Company (NISOC), Ahvaz, Iran

Copyright 2016 by the Geophysical Center RAS.

http://elpub.wdcb.ru/journals/rjes/doi/2016ES000581-res.html
}

logs, well test, mud loss data, cores and image logs analyses [Thompson, 2000 Tingay et al., 2008]. Image logs and cores are the best methods for the analysis of reservoir parameters. However, cores have serious limitations such as high cost, low recovery in fractured interval, and changing core orientation during coring [Khoshbakht et al., 2009] Mohebbi et al., 2007]. The Asmari Formation (Oligo-Miocene) is a main petroleum reservoir of Iran. Petroleum production potential of the Asmari reservoir is about $85 \%$ of the crude oil due to abnormal vuggy porosity type resulted from natural fractures [Gholipour, 1998]. Therefore the study of the fractures in the Asmari reservoir is a serious subject up to now [Aghli,2013, Khoshbakht et al.,2009,2012]. It is cleared that fracture study and evaluation in any oilfield can be helpful in the complementary stage of the well, the determination of perforating depth, field development, directional drilling well program, fluid injection zone and fracture modeling. Image log studies reduce expenditure owing to the reducing coring depths and perforate zone determination. The presence of fractures has a considerable impact on permeability [Rezaee and Chehrazi, 2005]. Previous work indicated that lithological change and sedimentary heterogeneity such as grain composition, cementation relative to the stress filed, 


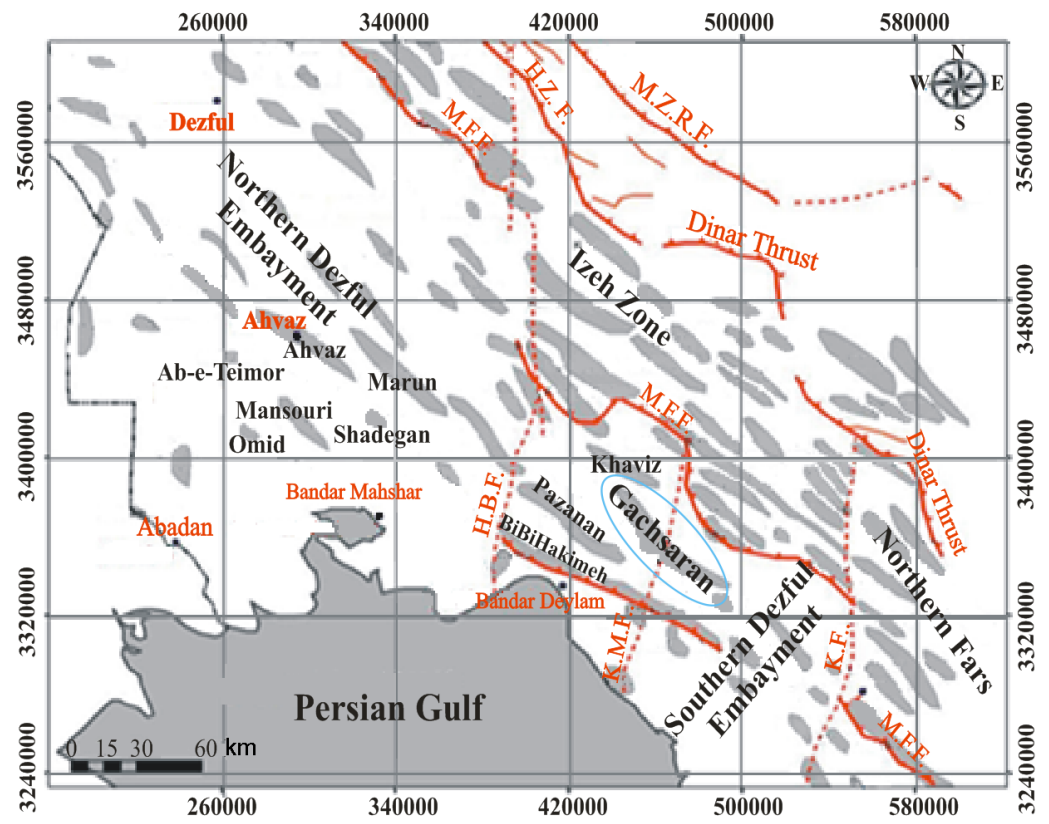

Figure 1. Main hydrocarbon oil fields position in Iranian Zagros range [Sherkati and Letouzey, 2004. Abbreviations are: M.Z.R.F.: Main Zagros reverse Fault, M.F.F.: Mountain Front Fault, H.Z.F.: High Zagros Fault, K.F.: Kazerun fault, K.M.F.: Karg-Mish fault, H.B.F.: Hendijan-Bahregansar fault.

can be influenced rock behavior and have a visible effect on the fracture density and distribution [Massiot et al., 2015 . McQuillan, 1973. Fracture spacing has also been related to the rock properties and bed thickness of the adjacent rock unit as well as the rock properties of fractured bed [Bai and Pollard, 2000. The velocity deviation log, which is calculated by combining the sonic log with the neutron or density $\log$, provides a tool to obtain well information on the predominant pore type in carbonates [Anselmetti and Eberli, 1993. The present work is an attempt to indicate the role of fracture on the reservoir parameters and the role of lithology on the fracture parameters. For this aim petrophysical and image logs are used simultaneously.

\section{Geological Setting}

Zagros fold-thrust belt extends about $2000 \mathrm{~km}$ from southeastern Turkey through northern Syria and Iraq to western and southern Iran [Alavi, 2004]. Structurally, Zagros basin is placed in the north of the Arabian plate. The studied field is located in Dezful Embayment of Zagros basin in SW of Iran (Figure 1).

Geological history of this basin indicated a long time subsidence and deposition which interrupted by short time uplift. Folding process of this basin occurred in Miocene and Pliocene and continued until now which formed long anticlines [Ahmadhadi et al., 2008, Mottie, 1995 Twerenbold and McQuillan, 1962. These anticlines constitute most of oil traps in this basin. Dezful Embayment (SW Iran) is a part of Zagros fold and thrust belt [Alavi, 2004 2007 McQuarrie, 2004.

The Asmari Formation (Oligo-Miocene) is composed of light gray (locally buff to white) shallow marine Hippurite bearing limestone (grainstone, pelletal packstone, dark bioclastic wackestone) with intercalations of black fissile shale and broken by several intraformational disconformities [Alavi, 2004]. The Gachsaran oil field is located at the south Dezful Embayment limited by many faults which has caused difficulty in structural analyses. The studied oil field characterized by 50 miles long and 6 miles wide $(80 \mathrm{~km} \times 9.6 \mathrm{~km})$. Understudy drilled well in this field is in the south limb in the anticline which has higher dip rather north and this limb is reversed (Figure 1p).

\section{Methods and Materials}

Electrical images are produced by placing pads with arrays of electrodes maintained at a constant electrical potential against the borehole wall, and measuring the current drop as the electrodes travel along the borehole wall [Ekstrom et al., 1987. Ye and Rabiller, 1998. Data from multiple electrodes are combined to produce electrical conductivity images. Because a current is being passed into the borehole wall, this technique actually measures the properties of a volume of rock within a few inches out of the borehole. The azimuthal coverage of the image and its resolution is determined by the size and number of electrodes, their arrangement, the pad dimensions, and the borehole diameter. 


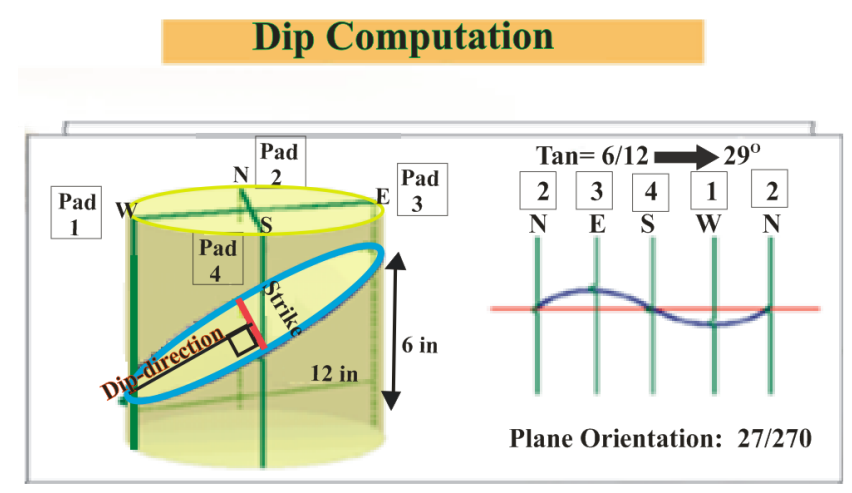

Figure 2. Schematic illustration of fracture plane intersecting a cylindrical borehole, indicating how the strike and dip of the fracture is interpreted from televiewer log images of the intersection between the fracture plane and the borehole wall.

When the image is "unrolled" and displayed from $0^{\circ}$ to $360^{\circ}$, linear features intersecting the borehole appear as sinusoids [Rider, 1996] Assuming that the images are properly oriented to geographic north, the amplitude and minimum of the sinusoids can be related to the dip and azimuth of the associated feature, respectively, and consequently provide fundamental information regarding the encountered formation Figure 2. In this study, FMI image log as the main data and VDL is complementary data were used. Image $\log$ is a "pseudo-picture" of borehole wall which image the physical property of borehole wall such as electrical resistivity or acoustic impedance. In the first method resistivity of borehole wall is converted into high resolution resistivity image of wall. There are 2, 4, 5 or 8 pads on an imaging tool Figure 3). Each pad covers limited part of borehole wall [Serra, 1989]. The FMI tools have an azimuthal resolution of $192^{\circ}$ capable of radial micro resistivity measurements (vertical resolution: $0.2^{\prime \prime}$, vertical sampling: $0.1^{\prime \prime}$, depth of investigation: 30") [Schlumberger, 1994]. The images are carefully described to characterize fractures and other geological features and finally the image results were correlated with other data. In this study, image logs were processed and interpreted by the CIFLOG GEOMATRIX software. CIFLog-GeoMatrix integrated logging data interpretation and processing software uses Java's self balancing technology to realize cross-platform and multi-operating system processing without need to convert logging data [Dawei et al., 2013 Zhen, 2013. Based on the key special projects of the State and China National Petroleum Corporation (CNPC), CIFLog-GeoMatrix, integrated software for log processing and interpretation, is available for Windows, Linux, and Unix operating systems and with multiple languages. This software exclusively adopts a plug-in design that integrates conventional logging, imaging logging, special logging, and LEAP800 logging interpretation. Also, it features a userfriendly graphical user interface (GUI), powerful interactivity, and accurate and reliable interpretation methods while supporting multi-language secondary development.

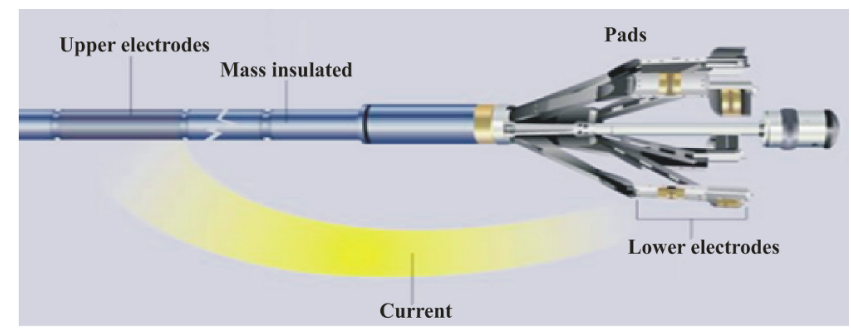

Figure 3. FMI tool and pads on the tool.

\section{Velocity Deviation Log}

The velocity deviation log, which is calculated by combining the sonic log with the neutron or density log, provides a tool to obtain well information on the predominant pore type in carbonates [ Wang and Nur, 1990]. Velocity deviation characterizes with three zones.

(a) Positive deviations - It indicates relatively high velocities in regard to porosity, and are caused mainly by porosity that is integrated in a frame like fabric of where the pores commonly are not connected. A positive deviation thus also may indicate low permeability.

(b) \pm Zero deviations - Zones with small deviations $( \pm 500 \mathrm{~m} / \mathrm{s}$ or less) represent sections that follow the predictions by the time-average equation. These zones are dominated by interparticle, intercrystalline, or high micro porosity. All of these pore types are particularly predominant in a sediment just after deposition, when original grains or micrite are simply packed together.

(c) Negative deviations - The larger scale fractures can be detected with the logging tools and yield lower velocities than the undisturbed rock. In addition, buried fractures are normally closed or, in regard to total porosity, are relatively insignificant, so that the neutron porosity is not significantly reduced. As a result, fracturing produces negative deviations [Anselmetti and Eberli, 1999 .

\section{Discussion}

After analyzing image logs in the well (Figure 4) software has this facility to show the data in stereo nets, rose diagrams and histograms. Because of the importance of open fractures (about 700) and bedding in this study (based on this study purpose), they were determined on image logs. Fracture density and fracture aperture was calculated for the well. After the analysis of electric image logs in the studied wells several feature such as open fracture, resistive fracture, conductive seam and bedding identified in this well. Fracture and bedding identified in the image log because is important in this research. After identifying the fracture, fracture density and aperture correlated with image log. To determine of lithology, petrophysical logs such as DT (acoustic log), NPHI (neutron porosity), PEF (photoelectric factor), RHOB (density porosity) were used. To find the effect of lithology on the fracture generation and fracture parameters, image log 


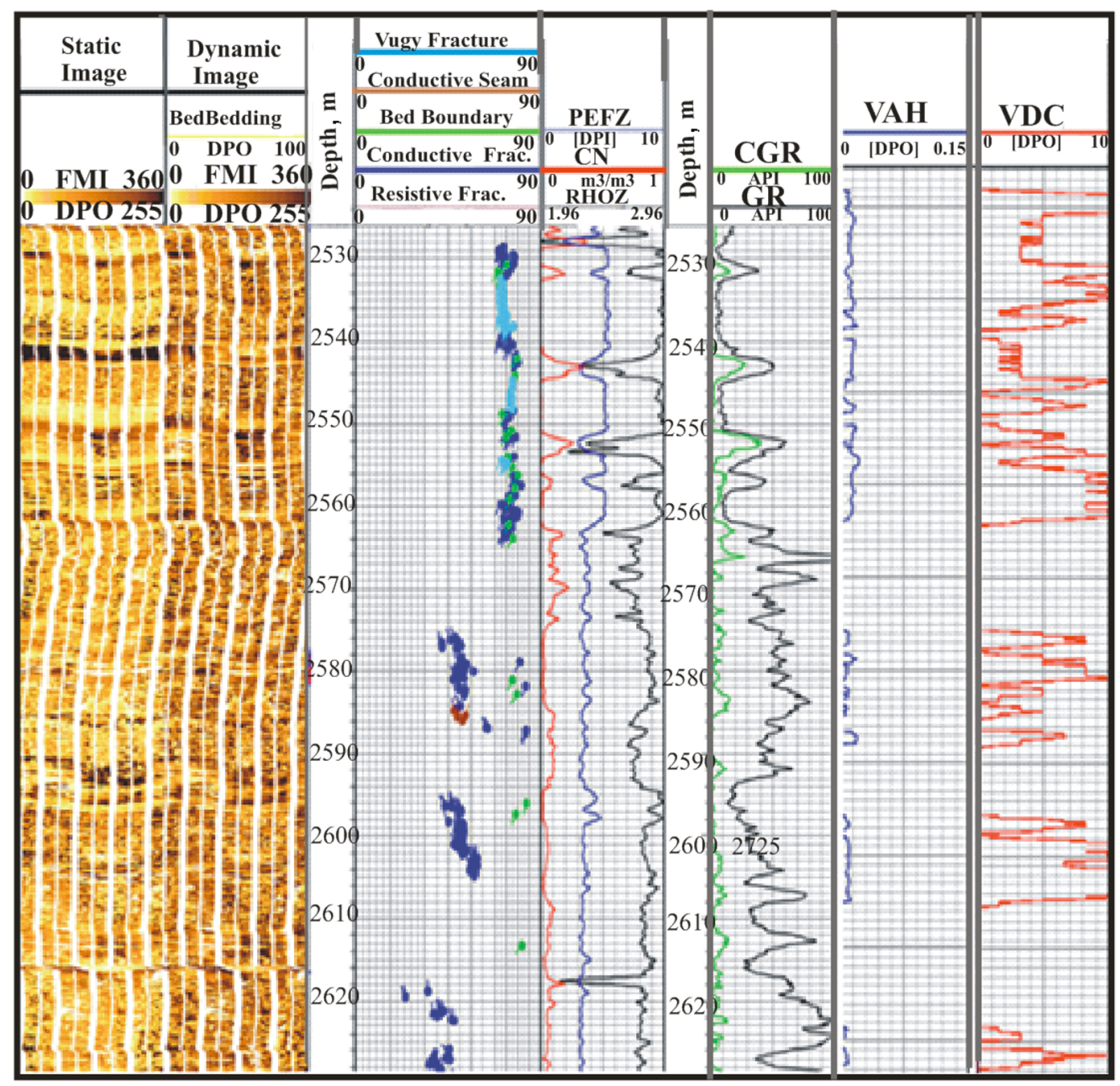

Figure 4. Image log and petrophysical logs in the understudy well. Abbreviations are: FMI: formation micro image, PEFZ: photoelectric factor, CN: compensate neutron, RHOZ: density log, CGR: compensate gamma ray, GR: gamma ray, VAH: apparent hydrolic fracture aperture, VDC: fracture density.

correlated with lithology and VDL Figure 5). The correlation showed that in depth, within thin bedded dolomite layers, fracture density is higher and velocity deviation is more negative.

Structural analyses in the Gachsaran oilfield indicated that Asmari Formation is a fracture reservoir. Fracture has two sets with two directions in the well: discontinuous fracture has dip within $8-49^{\circ}$ with azimuth $10-20$ and $330-360$, continuous fracture has higher dip rather discontinuous and are between $53-82^{\circ}$ with azimuth 200-230 (Figure 6). Two sets identified for the resistive fracture are scattered in dip, strike and azimuth. In this set, azimuths are 120 and 319, dips are 62 and 19 (Figure 7). Most fracture existing in the upper zone of the Asmari Formation. in this field, considering the general pattern of fractures, it is evident that they are related to the folding and are mainly classified as longitudinal, transverse, and oblique. The main fracture set has different orientation as the bedding. Strike in this set is almost N75E. The other fracture set is same oriented relative to the bedding and is considered as a longitude set. Dominant strike in this set is S55E. Continuous fracture has a same strike with bedding and type of fracture in this is longitudinal and fractures with strike of $\mathrm{N} 65 \mathrm{~W}$ are dominant in this well and are transvers.

The full-bore micro imager clearly indicate layering/bedding throughout the logged interval In the image log, bedding boundary is defined as a plane which two dimensions of it show different resistivity or acoustic impedance; therefore in image log bedding appears as abrupt change in image color which usually could be seen in all pads. These lines are easily correlated from pad to pad and are visible on static images and correspond to the surface or boundaries separating two beds of different lithology [Serra, 1989]. So the dips computed from the first type of layer/bed boundaries 


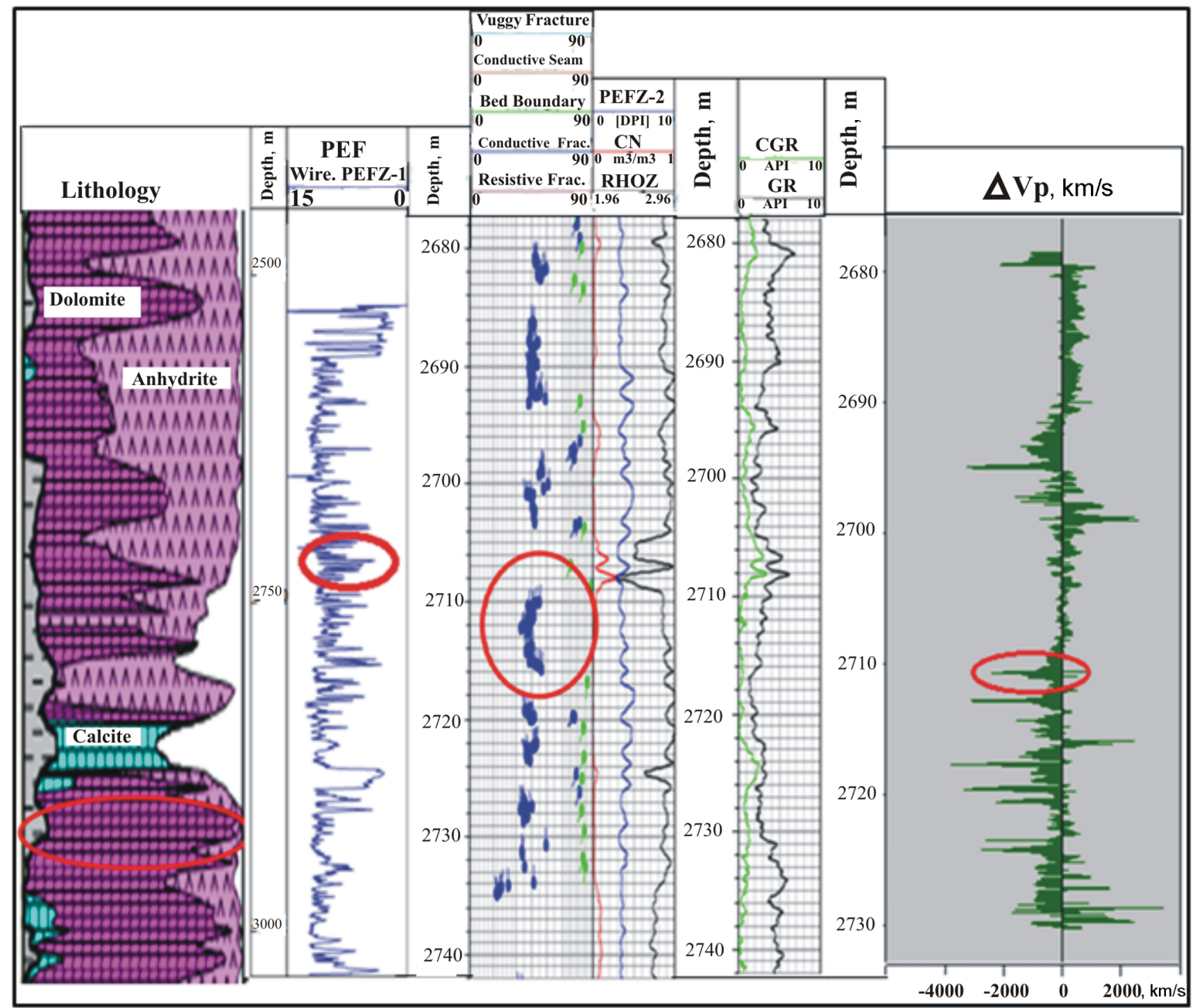

Figure 5. Comparison between lithology, image log and VDL showing negative values of VDL in zone with thin bedded dolomite layer. Abbreviations: PEF: photo electric factor, $\Delta V p$ : variation of velocity deviation.

are classified into high confidence (HC) bedding dips, and those from the uneven and vague boundaries are classified as low confidence (LC) bedding dips. In the upper Asmari, very thin shaly layers and anhydrite/limestone are abundant. Very thin lamination in upper Asmari carbonate and dense streak were indicators of bed boundary. In the middle part of Asmari, the quantity of bed boundaries was very limited and formation changes to massive limestone with anhydrite nodules. In this zone, variation of texture formed vague bed boundaries. Dips of bedding are very high between $53-89^{\circ}$ with azimuth $180-240$ but dominant azimuth is 218 (Figure 8). In spite of high dip bedding it must be considered that this feature indicates the role of reverse limb.
The Lithology can be one of important factor in controlling fracture distribution. Dolomite reservoirs are important sources of hydrocarbons, and their fluid flow pattern is commonly influenced by fractures. Fracture architecture depends on the rock properties at the time of fracturing (particularly subcritical crack index). Lithology and bed thickness are primary controls the fracture density, fracture aperture and orientation, reflecting the fact that different rock unit are mechanically distinct. Fracture density has been correlated with the mineralogical composition of the matrix grain, porosity and bed thickness. More brittle rocks will have more density fracture rather less brittle rocks. The primary brittle constituent within a rock are quartz, dolomite 


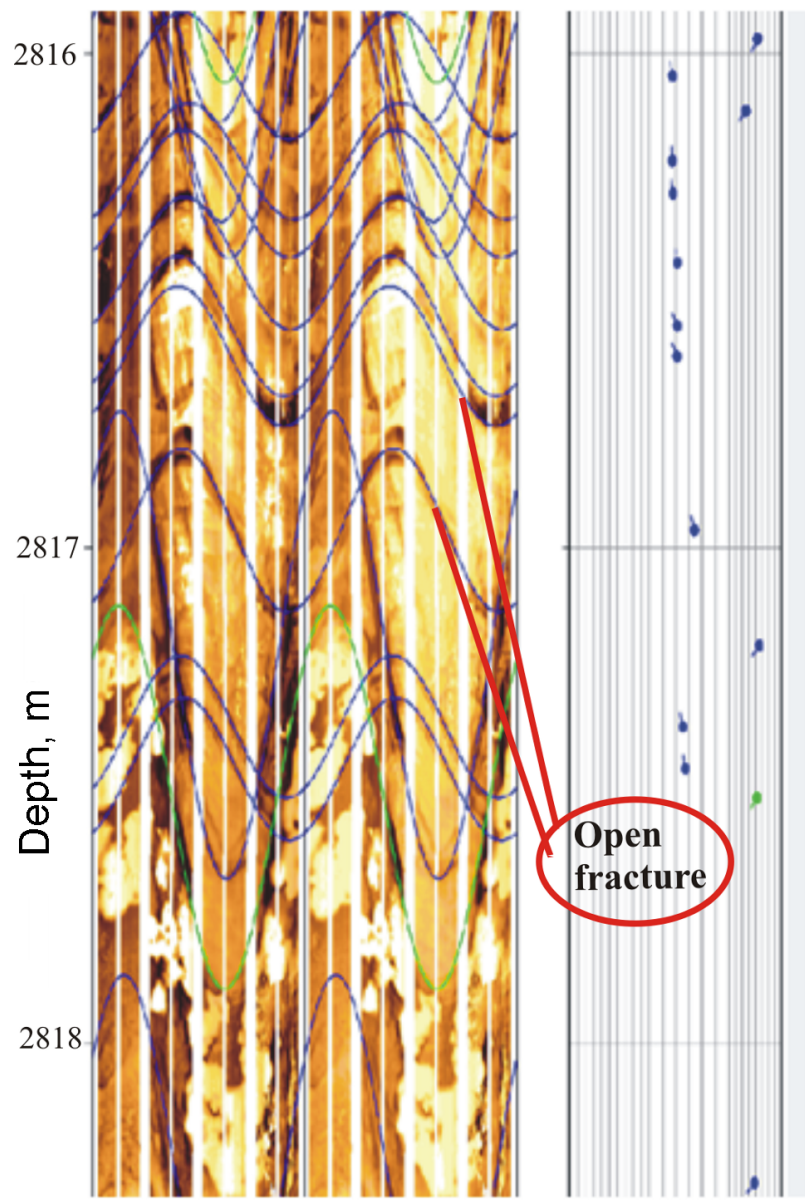

\begin{tabular}{|c|c|c|c|}
\hline Vell name= & 7-35-FMI- 035PUC & Top zone $=$ & $2525.7278 \mathrm{~m}$ \\
\hline T & $25.725098 \mathrm{~m}$ & Bottom zone $=$ & 3033.2173 \\
\hline Bottom = & $033.2197265625 \mathrm{~m}$ & & \\
\hline
\end{tabular}

\begin{tabular}{|l|l|}
\hline Set Number & Number of Dip \\
\hline
\end{tabular}

Conductive fracture

729
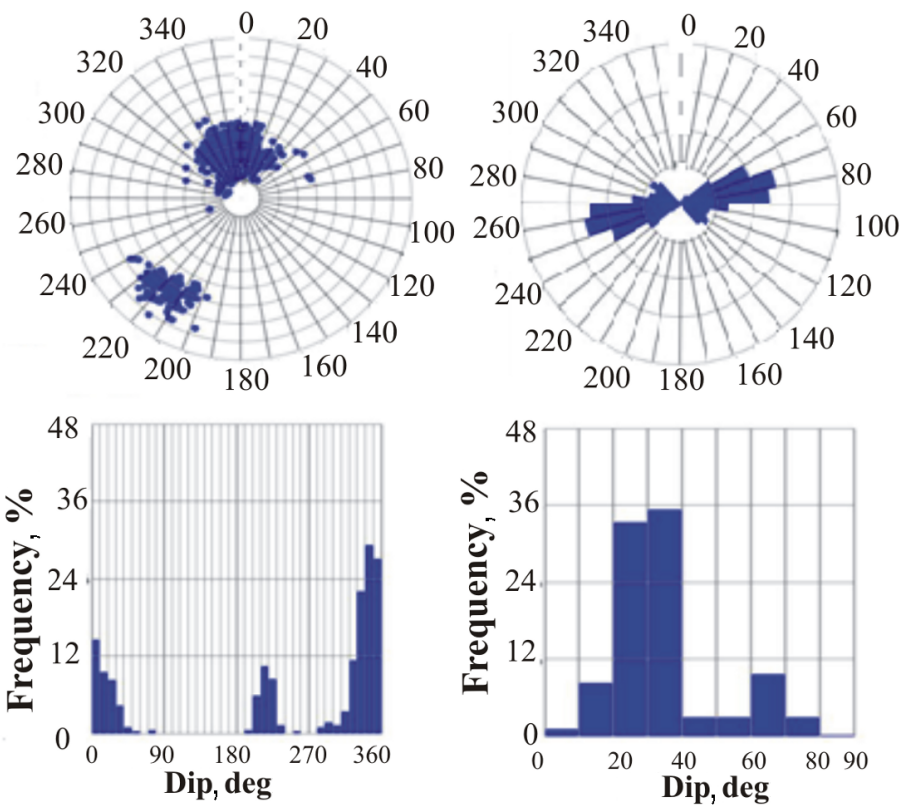

Figure 6. Open fracture on the image log, Stereonet rose diagrams and histograms.

and calcite. However, it should be noted that the elastic properties of a given rock unit which have a direct influence upon fracture density need not always associate with the amount of brittle constitute. According our results, it has been observed that when condition and all other rock parameters are equal, thin beds will higher fracture density rather thicker bed in the reservoir. In the present study, dominated mineral is dolomite and anhydrite, calcite and shale are little. It was evident that high density and high aperture fracture are correlated well (Figure 9). It showed that the fracture occurred in areas with thin bed and pure dolomite layers has high aperture (Figure 10) and fracture density is more dependent to bed thickness to lithology (Figure 11).

To evaluating the dominant pores pattern and fractures detection, VDL log was drawn using Sonic and Neutron digital data for the Asmari reservoir. In this well, generally, there is an inverse relationship between porosity and velocity, so velocity decreases with increasing porosity [Wyllie et al., 1956. Velocity deviation $\log$ (VDL) is a correlated method which is drawn with sigma plot 12 software and correlated with image log and lithology. The correlation of high fracture density, fracture aperture and negative deviation in this zone showed that fracture is higher correlated to VDL (Figure 12). Fracture having zone on the image log and VDL shows high correlation with the mineralogy determined with petrophysical log in Geolog.7.1 software. All data revealed that the Asmari reservoir consisted lithologically of dolomite, limestone. Anhydrite is also detected as a minor element (20-30\%) but decreased towards the base of Asmari Formation and formed Kalhor member. All data revealed that fractures can be effected the reservoir properties and for this aim image log, lithology and VDL were used. It was found that fractures are the most important features in the reservoir especially in the upper Asmari zones. In this field, production is controlled by a combination of fractures and vugy pores. Also reservoir zones with high rate of production characterized with continuous fractures with high aperture rather than discontinuous fractures. Correlated with density fracture (VDC) and aperture fracture with VDL showed that in the areas with high aperture and high fracture density velocity deviation, there is the highest negative deviation values which is indirectly indicated the association of aperture 


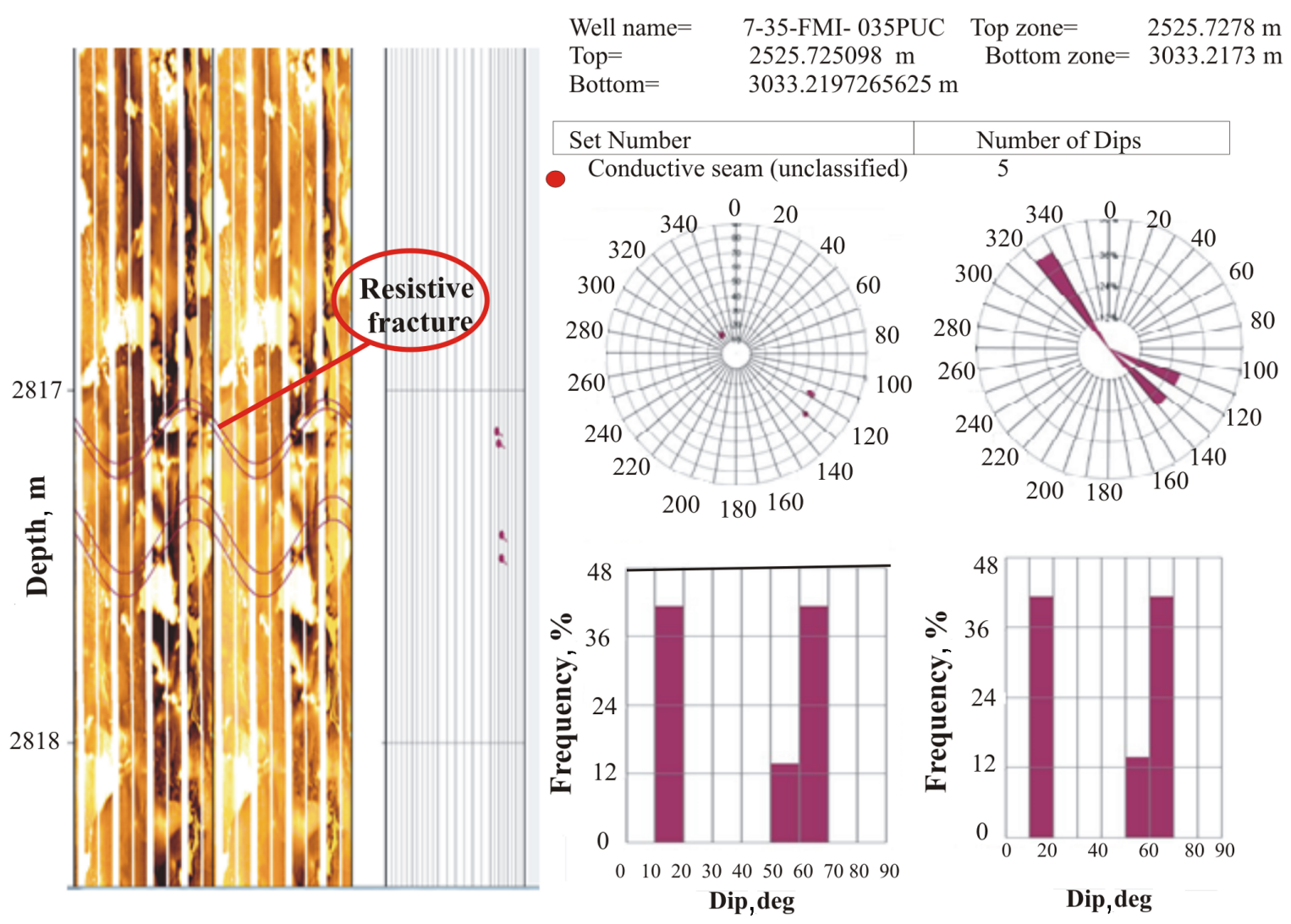

Figure 7. Resistive fractures on the image log, Stereonet rose diagrams and histograms.

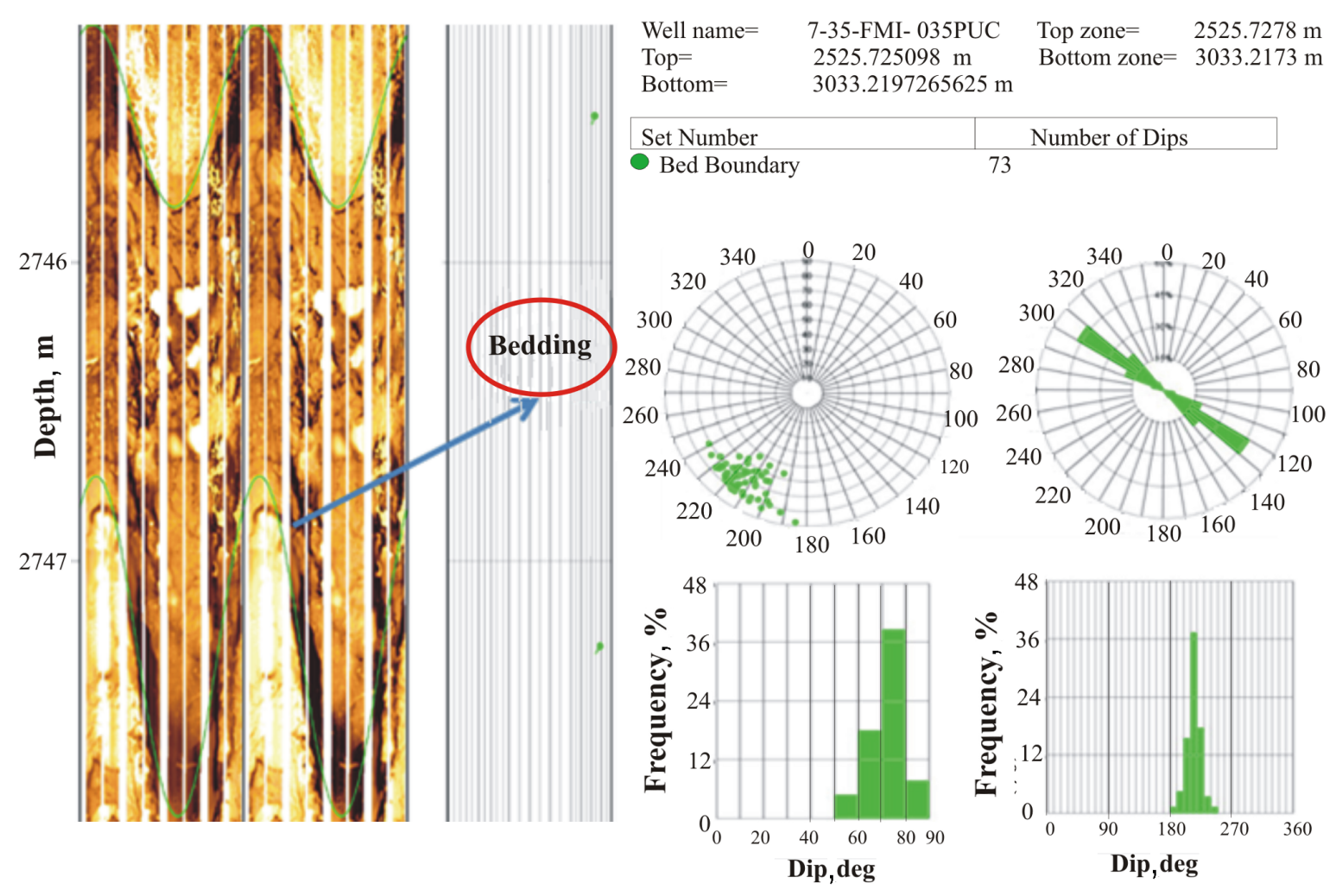

Figure 8. Bedding on the image log, stereonet rose diagrams and histograms. 


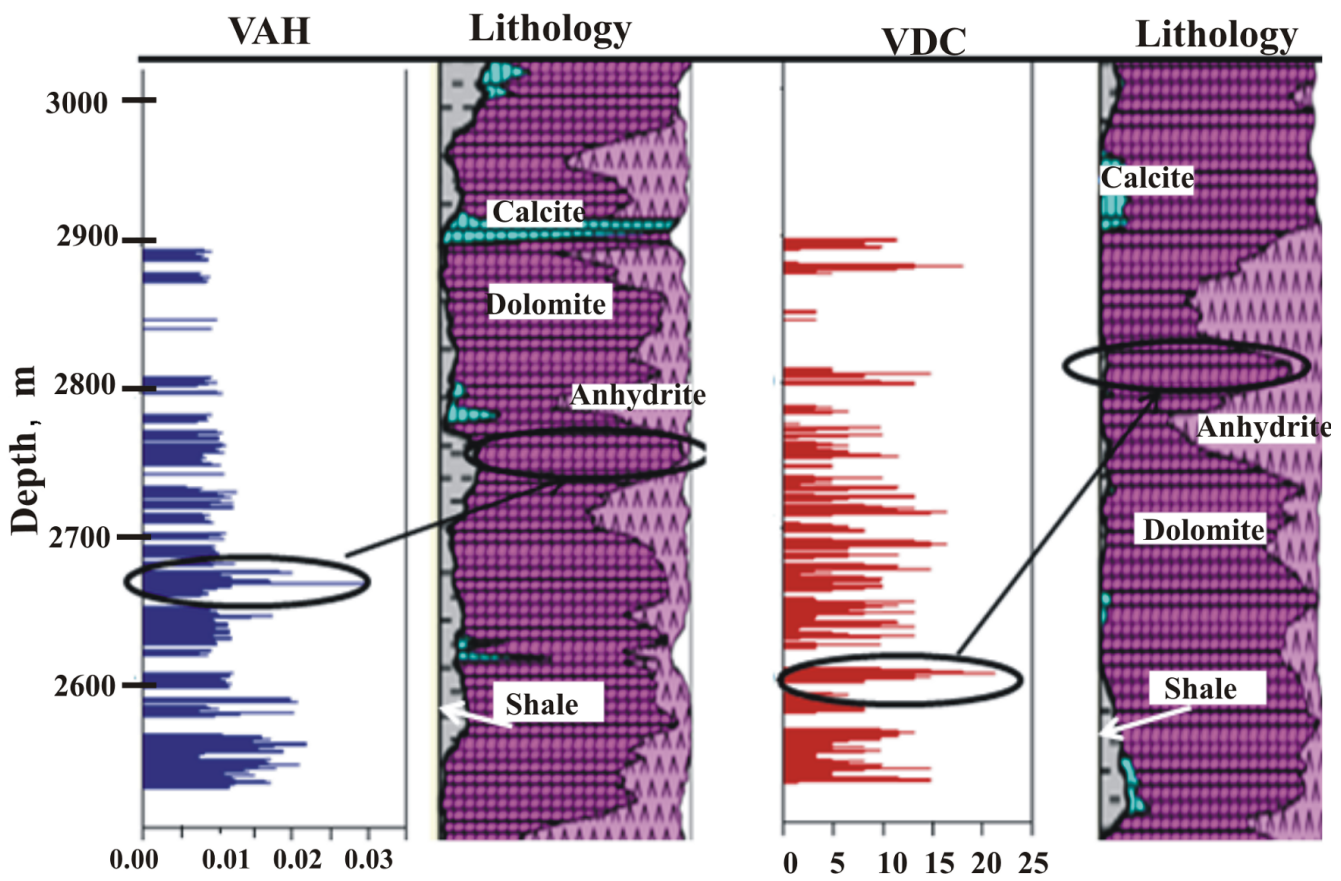

Figure 9. Role of lithology on fracture density (VDC) and fracture aperture (VAH).

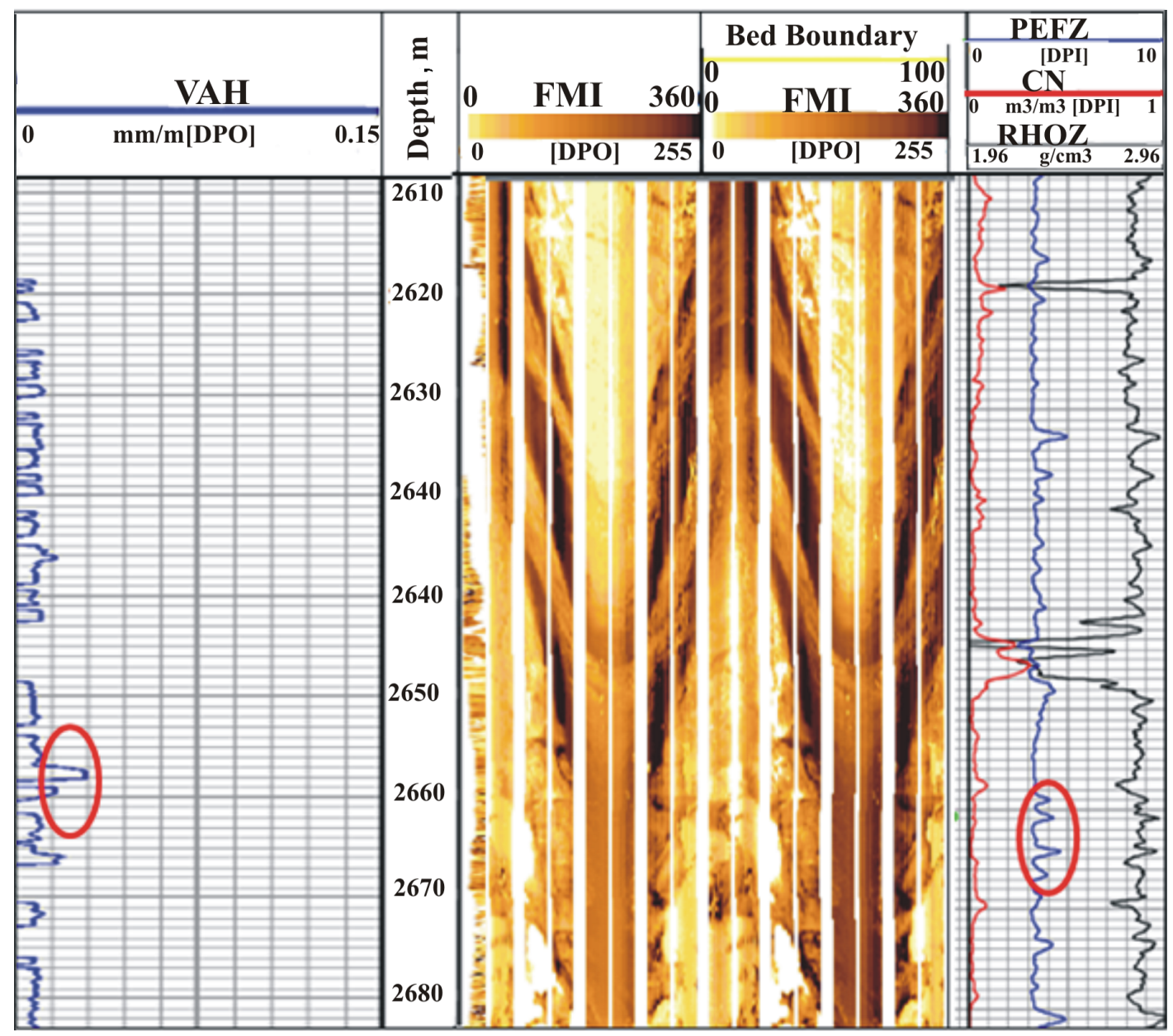

Figure 10. Comparison between the zone responses having fractures with higher aperture (VAH) and petrophysical log (PEF). 

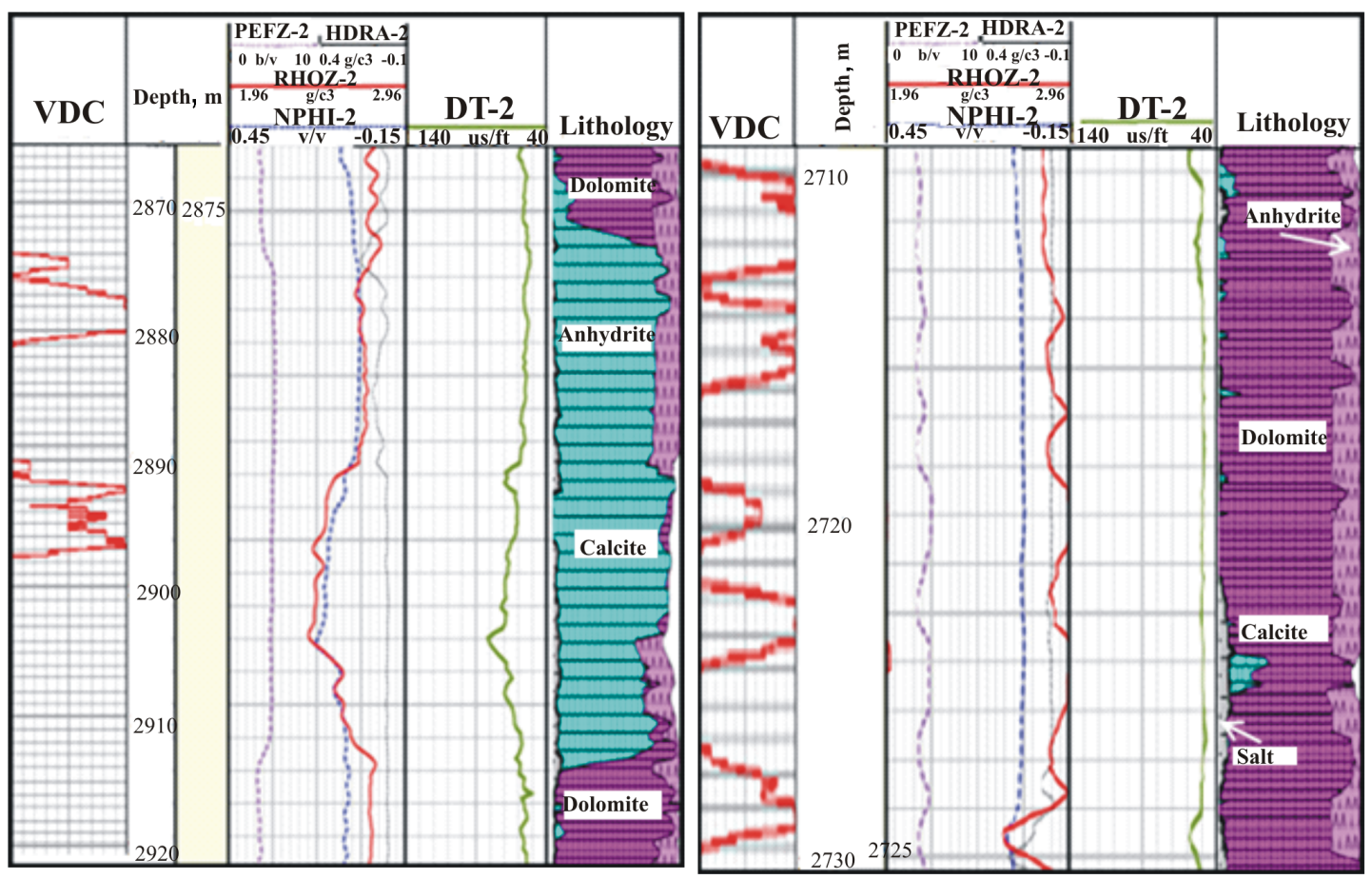

Figure 11. The plot indicates the effect of mineralogy on the fracture density. Abbreviations: NPHI: neutron porosity, DT-2: sonic log.

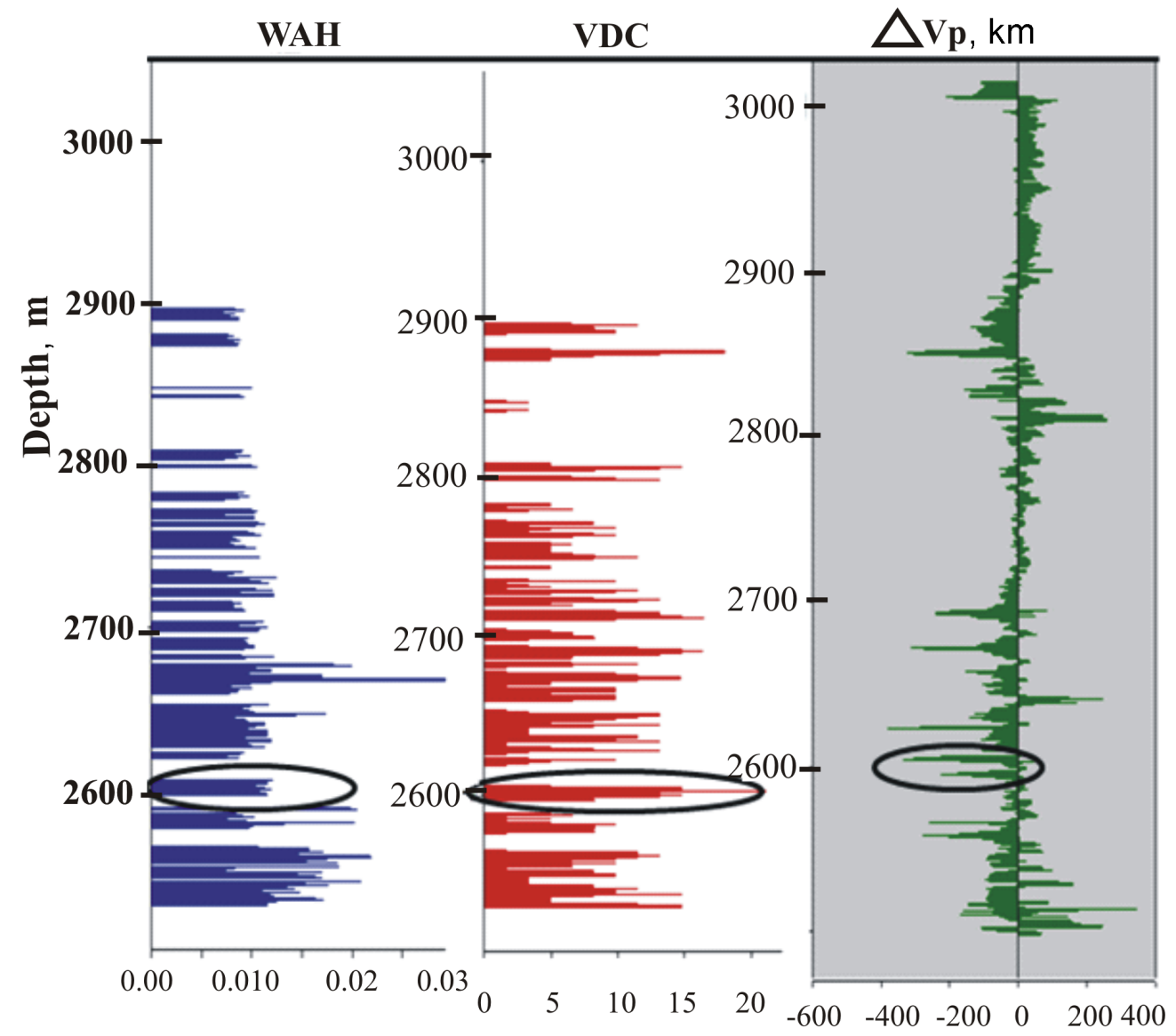

Figure 12. The plot shows more negative values of VDC in zones with high fracture aperture and so high fracture density velocity deviation. VAH controlled deviation of VDL values. 
and fracture density in controlling the permeability. In view of the effect of lithology in fracture parameters such as density and aperture, VDL and mineralogy are correlated well, and they show the zones with pure dolomite, fracture apertures are higher than zones with dolomite and anhydrate, and the fracture density in thin bedded dolomites is higher (shown on the image log and VDL).

\section{Conclusion}

The Asmari reservoir consisted of dolomite, limestone and anhydrite. To determine the lithology impacts on the fracture parameters and carbonate reservoir properties of Asmari Formation in Gachsaran oilfield, SW Iran, image logs, VDL and lithology results were compared. Image logs interpretation showed that fracturing was occurred in different horizons. There are more than 700 open fractures and so the Asmari Formation can be considered as a fractured reservoir. N75E fracture set as transverse pattern is dominant. They are characterized by strike N75E and are discontinuous. The other set as longitude has strike S55E, and showing a same strike with bedding, and are to be contemporaneous fractures with folding. Bedding with strike N55W has a high dip between $53-89^{\circ}$ which indicate reverse limb in the anticline. Due to well correlation between all data and fracture parameters it can be concluded that the fracture parameters are controlled by lithology and tectonic activity. VDL as a method for the detection of fracture zones showed high correlation of fracture density log (VDC) and fracture aperture (VAH). The last factor is higher in the zones consisted of pure dolomite. Zones having thin bedded pure dolomite are presenting better reservoir quality as well.

Acknowledgments. The authors would like to acknowledge the support and advice of colleagues at National Iranian Oil Company (NIOC), Geological development section, and the Research Manager of Shahid Chamran University of Ahvaz for their encouragements. We would also like to express frankly thanks to anonymous referees for their critical points to improve the quality of the paper.

\section{References}

Aghli, G. (2013), Fracture analysis of the Asmari reservoir in Balarud oilfield using the image logs, M. Sc. Dissertation, Shahid Chamran University, Ahvaz, Iran.

Alavi, M. (2004), Regional stratigraphy of the Zagros fold-thrust belt of Iran and its proforeland evolution, American Journal of Science, 304, No. 1, 1-20, doi:10.2475/ajs.304.1.1 Alavi, M. (2007), Structures of the Zagros fold-thrust belt in Iran, American Journal of Science, 307, No. 9, 1064-1095, doi:10.2475/09.2007.02

Ahmadhadi, F., J. Daniel, M. Azzizadeh, O. Lacombe (2008), Evidence for pre-folding vein development in the Oligo-Miocene Asmari Formation in the Central Zagros Fold Belt, Iran, Tectonics, 27, No. TC1016, 1-22. doi:10.1029/2006TC001978

Anselmetti, F. S., G. P. Eberli (1993), Controls on sonic velocity in carbonates, Pure \& Applied Geophysics, 141, No. $2-4, \quad 287-323$, doi:10.1007/BF00998333
Anselmetti, F. S., G. P. Eberli (1999), The velocity-deviation log: A tool to predict pore type permeability trends in carbonates drill holes from sonic \& porosity or density logs, $A A P G$ Bulletin, 83, No. 3, 450-466.

Bai, T., D. D. Pollard (2000),

Fracture spacing in layered rock: A new exploration based on the stress transition, Journal of Structure Geology, 22, 43-57, doi:10.1016/S01918141(99)00137-6

Dawei, L., L. Ning, W. Hao, W. Dong, Y. Zheng, Y. Mingfa (2013), Logging Evaluation Technologies of Complex Lithologic Reservoir, 24 pp., Science \& Technology Management Department, Petroleum Technology Development Corporation, China.

Ekstrom, M. P., C. Dahan, M. Y. Chen, P. Lloyd, D. J. Rossi (1987), Formation imaging with microelectrical scanning arrays, Log Analyst, 28, 294-306.

Gholipour, A. M. (1998), Patterns and structural positions of productive fractures in the Asmari Reservoirs, Southwest Iran, Journal of Canadian Petroleum Technology, 37, No. 1, 4450, doi:10.2118/98-01-07

Khoshbakht, F., H. Memarian, M. Mohammadnia (2009), Comparison of Asmari, Pabdeh and Gurpi formations fractures, derived from image log, Journal of Petroleum Science and Engineering, 67, No. 1-2, 65-74, doi:10.1016/j.petrol.2009.02.011

Khoshbakht, F., M. Azizzadeh, H. Memarian, G. H. Nourozi, S. A. Moallemi (2012), Comparison of electrical image $\log$ with core in a fractured carbonate reservoir, Journal of Petroleum Science and Engineering, 86-87, 289-296, doi:10.1016/j.petrol.2012.03.007

Massiot, C., D. D. McNamara, A. Nicol, J. Townend (2015), Fracture width and spacing distributions from borehole televiewer logs and cores in the Rotokawa Geothermal Field, New Zealand, Proceedings World Geothermal Congress, Melbourne, Australia, 19-25 April p. 12, International Geothermal Association, Melbourne, Australia. (https://pangea.stanford.edu/ ERE/db/WGC/papers/WGC/2015/12030.pdf)

McQuarrie, N. (2004), Crustal scale geometry of the Zagros fold-thrust belt, Iran, Journal of Structural Geology, 26, 519535, doi:10.1016/j.jsg.2003.08.009

McQuillan, H. (1973), Small scale fracture density in Asmari formation of southwest Iran and its relation to bed thickness and structural setting, American Association of Petroleum Geology Bulletin, 47, No. 12, 2367-2385, doi:10.1306/83d9131c$16 \mathrm{c} 7-11 \mathrm{~d} 7-8645000102 \mathrm{c} 1865 \mathrm{~d}$

Mohebbi, A., M. Haghighi, M. Sahimi (2007), Conventional logs for fracture detection and characterization in one of the Iranian field, International Petroleum Technology Conference, 4-6 December, Dubai, U.A.E. p. 8, Int. Petr. Techn. Conf., Dubai. doi:10.2523/IPTC-11186-MS

Mottie, H. (1995), Geology of Iran; Petroleum geology of Zagros, Geological Society of Iran Publication 37(2), p. 1009, Geological Society of Iran, Tehran.

Nelson, R. A. (2001), Geologic Analysis of Naturally Fractured Reservoirs, 2nd ed., 332 pp., Gulf Publishing, Houston, Texas.

Rider, H. (1996), The Geological Interpretation of Well Logs, 280 pp., Gulf Publishing, Huston, Texas, USA.

Rajabi, M., S. Sherkati, B. Bohloli, M. Tingay (2010), Subsurface fracture analysis and determination of in-situ stress direction using FMI logs: An example from the Santonian carbonates (Ilam Formation) in the Abadan Plain, Iran, Tectonophysics, 492, No. 1-4, 192-200, doi:10.1016/j.tecto.2010.06.014 Rezaee, M. R., A. Chehrazi (2005), Fundamentals of Well Log Interpretation, University of Tehran, Tehran. (in Persian) Serra, O. (1989), Formation Micro Scanner Image Interpretation, Schlumberger Education Services, Houston.

Serra, O., L. Serra (2004), Well Logging: Data Acquisition and Applications, 688 pp., Editions Technip, Paris.

Schlumberger (1994), FMI Fullbore Formation MicroImager, Schlumberger Education Services, Houston.

Schlumberger (2003), Using borehole imagery to reveal key reservoir features, Reservoir Optimization Conference p. 137, Chester, Tehran, Iran. 
Sherkati, S., J. Letouzey (2004), Variation of structural style and basin evolutionin in the central Zagros Izeh zone and Dezful Embayment, Iran, Marine and Petroleum Geology, 21, 535-554, doi:10.1016/j.marpetgeo.2004.01.007

Twerenbold, E. F., H. McQuillan (1962), Asmari fold and fractures pattern study, Private Report 999, p. 33, Iranian Oil Consortium, Tehran, Iran.

Thompson, L. B. (2000), Fractured reservoirs: Integration is the key to optimization, Journal of Petroleum Technology, 52, No. 2, 52-54, doi:10.2118/56010-JPT

Tingay, M., J. Reinecker, B. Müller (2008), Borehole breakout and drilling-induced fracture analysis from image logs, World Stress Map Project, p. 1-8, GFZ German Research Centre for Geosciences, Potsdam. (https://www.researchgate.net/publication/242115376_Borehole_breakout_and_drilling-induced_fracture_analysis_from_image_logs)

Wang, Z., A. Nur (1990),

Dispersion analysis of acoustic velocities in Rocks, Journal of Acoustical society of America, 87, No. 6, 2384-2395, doi:10.1121/1.399551
Wyllie, M. R. J., A. R. Gregory, L. W. Gardner (1956), Elastic wave velocities in heterogeneous \& porous media, Geophysics, 21, 41-70, doi:10.1190/1.1438217

Ye, S., P. Rabiller (1998), Automated fracture detection on high resolution resistivity borehole imagery, SPE annual technical conference and exhibition p. 777-784, Society of Petroleum Engineers, New Orleans, Louisiana. doi:10.2118/49300-MS

Zhen, N. L. (2013), SPE annual technical conference and exhibition, Oil Industry, China.

Khayyam Amiri, Babak Samani, and Bahman Soleimani, Department of Geology, Shahid Chamran University of Ahvaz, Ahvaz, Iran. (khaiamamiri@gmail.com; samani.babak@gmail.com; soleimani_b@scu.ac.ir)

Leila Shaban, National South Iranian Oil Company (NISOC), Studies office, Ahvaz, Iran. (leilashaban@gmail.com) 